\title{
As Novas Definições e Classificações dos Estados Intersexuais: o Que o Consenso de Chicago Contribui para o Estado da Arte?
}

\begin{abstract}
RESUMO
As anomalias da diferenciação sexual têm-se constituído em um formidável desafio quanto ao diagnóstico e à conduta, colocando o paciente, os familiares e os profissionais da equipe de saúde na difícil situação de definir a melhor opção quanto ao gênero de criação. Uma terminologia confusa e estigmatizante tem sido adotada e, nesse sentido, o Consenso de Chicago propõe várias modificações no sentido de minimizar os desconfortos graças a uma terminologia que nem sempre auxilia na solução de problemas. Os autores fazem uma análise crítica da classificação sugerida pelo Consenso, levantando a questão de que, na nova classificação, também não se resolvem certos problemas terminológicos e continua a se criar algum grau de estigmatização. Em primeiro lugar, a sugestão de se incluir o cariótipo no nome da doença supõe, erroneamente, que os pacientes não tenham conhecimento do que significa ser $46, X Y$ ou $46, X X$. Uma criança criada no sexo feminino com uma anomalia da diferenciação sexual (ADS) $46, X Y$ não vai entender porque está no sexo feminino se seu cariótipo é "masculino". A substituição do termo hermafroditismo verdadeiro por ADS ovotesticular está longe de resolver o problema de estigmatização causado por "hermafroditismo". O termo ovotesticular é claramente entendido como uma fusão entre ovário e testículo e não será aceito com "naturalidade". Se, por um lado, é muito satisfatório que a questão da nomenclatura seja discutida, por outro lado devemos escolher termos alternativos que sejam realmente neutros e não tragam, em si, a conotação de um sexo que pode não condizer com o escolhido para aquele paciente em particular. Um ponto em que todos concordamos é que a substituição de intersexo por anomalia da diferenciação sexual (ADS) ou, disorder of sex development (DSD), na língua inglesa, cai muito melhor e não dá a conotação de um "sexo intermediário" como o nome antigo proporcionava. (Arq Bras Endocrinol Metab 2007;51/6:1013-1017)
\end{abstract}

Descritores: Anomalia da diferenciação sexual; Intersexo; Hermafroditismo; Pseudo-hermafroditismo; Gônadas; Ambigüidade genital

\section{ABSTRACT}

New Definitions and Classifications of the Intersexual States: in Which the Chicago Consensus Has Contributed to the State of the Art?

Disorders of sex development have posed a tremendous challenge not only in the diagnosis but also in the treatment, placing the patient, the family members, and the health team in the difficult task of attributing the best sex of rearing for that specific patient. A confusing and stigmatizing nomenclature has been employed and the Chicago Consensus tried to minimize the discomfort with modifications of the current terminology. The authors perform a critical analysis of the Consensus, raising the question that the new terminology does not solve the problems and persist being stigmatizing to the patient and to the family. First of all, the inclusion of the karyotype in the name of the disease holds the false premise that the patients do not know the meaning of a $46, X Y$ or a $46, X X$ karyotype. A child raised in the female sex will not understand that her disease holds a "male" karyotype in its name $(46, \mathrm{XY}$ DSD). The substitution of ovotesticular DSD for true hermaphroditism maintains the stigma of the name since ovotesticular is easily perceived as ovarian and testicular tissues. If, on one hand, the recognition of using terms like intersex and hermaphroditism are stigmatizing, on the other hand, we need terms that are really neutral to not create problems of sexual identification. One point in which there is consensus is that the change of the term "intersex" for "disorder of sex development" is highly desirable and eliminates the idea of an "intermediate sex". (Arq Bras Endocrinol Metab 2007;51/6:1013-1017)

Keywords: Disorder of sex development; Intersex; Hermaphroditism; Pseudo-hermaphroditism; Gonads; Ambiguous genitalia

\section{perspectiva}

\section{DURVAL DAMIANI \\ GIL GUERRA-JÚNIOR}

\section{Unidade de Endocrinologia \\ Pediátrica do Instituto da Criança, Hospital das Clínicas da Faculdade de Medicina da Universidade de São Paulo - FMUSP (DD), São Paulo, SP, e Unidade de Endocrinologia Pediátrica do Departamento de Pediatria da Faculdade de Ciências Médicas da Universidade Estadual de Campinas - UNICAMP (GG-J), Campinas, SP.}

Recebido em 23/1 1/06

Revisado em 02/02/07

Aceito em 22/02/07 
V ÁRIOS E CONTROVERSOS SÃO OS PROBLEMAS qUe circundam o assunto das anomalias da diferenciação sexual (ADS), ou, como referido na literatura inglesa, intersexo. Uma anomalia genital ocorre em 1 de cada 4.500 nascimentos (1), sendo fundamental para sua detecção precoce o cuidadoso exame dos genitais de todo recém-nascido. A investigação etiológica da ambigüidade genital não é simples e implica a atuação conjunta e integradora de vários especialistas com experiência no tema, para que se possa, chegando ao diagnóstico, propor uma conduta (2).

A nomenclatura vigente em livros de textos e em artigos científicos sobre o assunto foi desenvolvida por Theodor Albrecht Edwin Klebs, em 1876, no seu Handbuch der Pathologischen Anatomie. A classificação baseia-se na natureza da gônada presente e os três grupos básicos são o pseudo-hermafroditismo masculino (PHM = genitália ambígua com testículos), pseudo-hermafroditismo feminino $(\mathrm{PHF}=$ genitália ambígua com ovários) e hermafroditismo verdadeiro $(\mathrm{HV}=$ testículo e ovário com ou sem genitália ambígua). Com a descoberta dos cromossomos, alguns autores passaram a definir PHM como ambigüidade genital em presença de um cariótipo 46,XY e PHF como ambigüidade genital com cariótipo 46,XX, mantendo-se a anatomia gonadal como base para o diagnóstico de HV. Revisões recentes sobre o assunto adotam a classificação com base no tipo de gônada e na constituição cromossômica (3-14).

Já há vários anos, abolimos o termo intersexo dos diagnósticos, preferindo a expressão ADS, já que intersexo denota um sexo intermediário ou um terceiro sexo, o que não é adequado para os pacientes.

Definindo de forma bastante global, dizemos que uma ADS é a situação em que não há acordo entre os vários sexos do indivíduo, ou seja, o sexo genético, retratado pela sua constituição cariotípica 46,XX ou $46, \mathrm{XY}$, o sexo gonadal/hormonal, e o sexo fenotípico. Desta forma, poderemos ter casos com e sem ambigüidade genital. Por exemplo, uma criança com síndrome de Turner apresenta um cariótipo com perda total ou parcial de um dos cromossomos sexuais, em mosaico ou não, com gônadas em fita, e, no entanto, o seu sexo fenotípico é feminino, sem ambigüidade. Por outro lado, uma criança com insensibilidade androgênica parcial apresenta cariótipo 46,XY, testículos, e seu sexo fenotípico é ambíguo. Ambas as situações configuram uma ADS, porém uma apresenta genitália externa feminina normal, enquanto que na outra é ambígua.

A terminologia utilizada para caracterizar os grandes grupos tem levado a um certo estigma dos pacientes, já que envolvem o termo hermafroditismo e pseudo-hermafroditismo, que se mostram "estigmatizantes", tanto para os pacientes quando para os familiares. Mais ainda, a complementação do termo pseudo-hermafroditismo traz uma especificação de sexo (masculino ou feminino) que nem sempre está de acordo com o gênero assumido para aquele paciente. Assim, nas formas de insensibilidade completa a andrógenos, uma paciente com fenótipo feminino é definida, sindromicamente, como PHM, o que, convenhamos, cria muita confusão e incerteza na cabeça do próprio paciente e de seus familiares.

Para os pacientes, serem definidos como hermafroditas ou pseudo-hermafroditas causa constrangimento e apresenta uma conotação um tanto pejorativa da situação clínica apresentada.

Na tentativa de atenuar este problema decorrente da nomenclatura, bem como estabelecer normas de conduta diagnóstica e terapêutica, um grupo de especialistas membros da Lawson Wilkins Pediatric Endocrine Society (LWPES) e da European Society for Paediatric Endocrinology (ESPE) reuniu-se em Chicago (EUA), no final de 2005, para elaborar um consenso a respeito do assunto eliminando termos que pudessem causar dúvidas e/ou dar a conotação de o indivíduo ser ou estar sendo criado em um sexo incompatível com o seu diagnóstico, enfocando também aspectos relacionados ao manuseio, evolução a longo prazo e propondo estratégias para futuros estudos (15).

A tabela 1 apresenta a classificação proposta, substituindo termos tais como pseudo-hermafroditismo e hermafroditismo por termos que seriam mais bem “aceitos" pelos pacientes e pela sociedade em geral e não seriam tão confusos aos profissionais de saúde. Sempre que se tiver um diagnóstico preciso, este deve ser o preferido. Assim, ao invés de o diagnóstico ser ADS 46,XY para uma insensibilidade androgênica parcial, deve-se preferir o diagnóstico específico "insensibilidade androgênica parcial", que pode ser "refinado" com a explicitação do tipo de defeito do receptor androgênico, tal como: "insensibilidade androgênica parcial por mutação........ do receptor androgênico".

Observa-se como uma proposta positiva a substituição do termo "intersexo", que, indiscutivelmente, é dúbia. Anomalia da diferenciação sexual (ADS) ou Disorder of Sex Development (DSD) fica uma terminologia mais adequada. No entanto, o grupo que estabeleceu a proposta de consenso parte do princípio de que os cariótipos 46,XX e 46,XY são "códigos secretos" para os pacientes e para seus familiares, o que não é verdade. Com o amplo acesso aos meios de comunicação e de informação, qualquer um passa a relacionar 46,XX como um cariótipo do sexo feminino 
Tabela 1. Proposta de modificação de nomenclatura em Anomalias da Diferenciação Sexual.

\begin{tabular}{|c|c|}
\hline Nomenclatura prévia & Nomenclatura proposta \\
\hline Intersexo & $\begin{array}{l}\text { Anomalia da Diferenciação Sexual (ADS) } \\
\text { ou Disorders of Sex Development (DSD) }\end{array}$ \\
\hline Pseudo-hermafroditismo masculino & ADS $46, X Y$ ou \\
\hline $\begin{array}{l}\text { Sub-virilização em um homem } X Y \\
\text { Sub-masculinização num homem XY }\end{array}$ & $46, X Y$ DSD \\
\hline $\begin{array}{l}\text { Pseudo-hermafroditismo feminino } \\
\text { Virilização numa mulher XX } \\
\text { Masculinização numa mulher XX }\end{array}$ & $\begin{array}{l}\text { ADS } 46, X X \text { ou } \\
46, X X \text { DSD }\end{array}$ \\
\hline Hermafroditismo verdadeiro & $\begin{array}{l}\text { ADS ovotesticular ou } \\
\text { Ovotesticular DSD }\end{array}$ \\
\hline Homem XX ou Sexo Reverso XX & $\begin{array}{l}\text { ADS } 46, X X \text { testicular ou } \\
46, X X \text { testicular DSD }\end{array}$ \\
\hline Sexo Reverso XY & Disgenesia gonadal completa $46, \mathrm{XY}$ \\
\hline
\end{tabular}

e 46,XY, do sexo masculino. Muitas das decisões a respeito do gênero de criação não serão condizentes com tal interpretação. Por exemplo, numa insensibilidade completa a andrógenos, o novo diagnóstico fica sendo "ADS 46,XY" e o paciente é criado no sexo feminino. Acrescentar o cariótipo ao nome da disfunção não nos parece adequado pois cria os mesmos problemas que o Consenso tenta resolver.

Por outro lado, substituir-se Hermafroditismo Verdadeiro por "ADS ovotesticular" acaba sendo a persistência da proposta de Klebs, em que se leva em conta o tipo de gônada para definir-se o diagnóstico. Fica claro que "ovotesticular" tem implicações de ovário e testículo. Um paciente com $\mathrm{HV}$ criado no sexo feminino acharia estranho que o nome de sua disfunção traz o termo "ovotesticular". Talvez chamarmos a condição de "ADS verdadeira" poderia resolver o problema e não criar novos estigmas pela nomenclatura.

Quanto aos pacientes "Homens XX" ou sexo reverso, a proposta "ADS 46,XX testicular" cria uma automática conotação de gênero de criação (masculino) e devemos lembrar que, enquanto $80 \%$ dos casos são homens fenotípicos e serão criados no sexo masculino, $20 \%$ apresentam genitália ambígua e podem, eventualmente, ser criados no sexo feminino. Voltamos, então, à difícil e constrangedora situação de uma menina ter no nome de seu diagnóstico um cariótipo "feminino" ao lado do nome da gônada masculina. Aliás, esta foi a razão por que a terminologia "insensibilidade androgênica" substituiu "testículo feminizante".

Antes do Consenso, Houk e cols. propuseram uma nova classificação com o objetivo de utilizar termos menos "pejorativos", tanto para os pacientes quanto para os profissionais de saúde. Fica clara, nesta tentativa de classificação, a mesma ênfase dada pelo
Consenso aos diagnósticos específicos, sempre que estiverem disponíveis. Assim, ao invés de falar ADS 46,XY num caso de insensibilidade androgênica, devese utilizar o diagnóstico específico "insensibilidade androgênica completa” ou "insensibilidade androgênica parcial". Se mais detalhes são conhecidos sobre a mutação do receptor androgênico, esta informação pode ser acrescentada ao diagnóstico. No entanto, esta primeira tentativa de classificação preserva termos como "intersexo", bem como introduz os cariótipos nos diagnósticos sindrômicos (16).

Portanto, nesta parte de nomenclatura, o consenso não resolveu totalmente os problemas a que se propôs e deveria ser revisado antes de sua pretendida aceitação.

Em relação à investigação e manuseio das ADS, foi decisão do Consenso que alguns conceitos gerais no cuidado de pacientes com ADS devem ser aplicados: (a) a atribuição de gênero deve ser evitada antes da avaliação de especialistas, (b) a avaliação e o manuseio a longo prazo devem ser feitos num Centro Médico com equipe multidisciplinar experiente, (c) todos os indivíduos devem receber um gênero, (d) uma via de comunicação fácil entre pais e equipe de saúde é essencial e encoraja-se a participação da família nos processos de decisão, (e) as preocupações dos pacientes e dos familiares devem ser respeitadas e tratadas num ambiente de confiança. A importância de grupos de apoio tanto para os familiares quanto para os próprios pacientes não deve ser descartada.

Não há muito para ser comentado nesses conceitos gerais e deve-se, por questões sociais e legais, não esquecer que o período em que a criança não é registrada, é um período em que ela não existe como cidadã, e medidas judiciais devem ser tomadas para 
garantir a este indivíduo, mesmo sem registro civil, acesso aos recursos disponibilizados a qualquer criança, tais como vacinação, obtenção de consultas em Centros de Saúde, deslocamentos de um Estado a outro, e assim por diante.

Em 2003, o Conselho Federal de Medicina do Brasil emitiu a resolução 1664/2003 tratando do assunto "Anomalias da Diferenciação Sexual" e propondo uma definição adequada do gênero e tratamento em tempo hábil (Art $2^{\circ}$ ); menciona também a necessidade de uma estrutura mínima que contemple a realização de exames complementares como dosagens hormonais, exames citogenéticos, de imagem e aná-

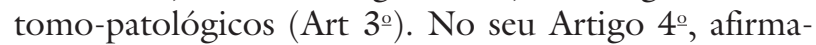
se: "Para a definição final e adoção do sexo dos pacientes com anomalias de diferenciação, faz-se obrigatória a existência de uma equipe multidisciplinar que assegure conhecimentos nas seguintes áreas: clínica geral e/ou pediátrica, endocrinologia, endocrinologia pediátrica, cirurgia, genética, psiquiatria, psiquiatria

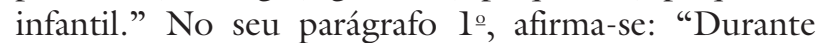
toda a fase de investigação, o paciente e seus familiares ou responsáveis legais devem receber apoio e informações sobre o problema e suas implicações." No Parágrafo $2^{\circ}$, afirma-se: "O paciente que apresenta condições deve participar ativamente da definição do

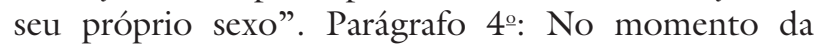
definição final do sexo, os familiares ou responsáveis legais e, eventualmente, o paciente, devem estar suficiente e devidamente informados de modo a participar da decisão do tratamento proposto. No Artigo 6o, enfatiza-se a importância de o tema "anomalias da diferenciação sexual" estar sendo discutido em eventos médicos, congressos, simpósios e jornadas, visando à sua ampla difusão e atualização dos conhecimentos na área (17).

O Consenso estabelece critérios que sugerem uma ADS, que incluem: (a) clara ambigüidade genital (exemplo, extrofia cloacal), (b) genitália com aparência feminina com aumento clitoriano, fusão labial posterior ou massa inguinal ou labial, (c) genitália com aparência masculina com criptorquidia bilateral, micropênis, hipospádia perineal isolada ou hipospádia leve com testículos não descidos, (d) história familial de ADS, tal como insensibilidade androgênica completa, (e) discordância entre a aparência genital e o cariótipo pré-natal.

Chama-se a atenção para o fato de que, embora a maioria dos casos seja reconhecida no período neonatal, apresentações em crianças maiores ou adolescentes incluem ambigüidade genital não reconhecida previamente, hérnia inguinal em meninas, puberdade atrasada ou incompleta, virilização em meninas, amenorréia primária, desenvolvimento mamário em meninos, hematúria cíclica em meninos.

Talvez o que o Consenso chama de "clara ambigüidade genital” exemplificando com extrofia cloacal seja um processo não relacionado à embriogênese normal do aparelho uro-genital e, talvez, devesse constituir um grupo à parte, já que se trata de um defeito embriogenético para o qual não se têm detectado genes específicos e no qual não ocorrem alterações hormonais. Importante salientarmos que micropênis isolado ou hipospádia leve com testículos não descidos devem ser incluídos como ADS e merecem investigação, dada a grande falta de associação entre distúrbios graves da determinação gonadal ou da diferenciação sexual com alterações "mínimas" na genitália externa. Nunca perder de vista que muitas crianças que nos procuram devido a "criptorquidia bilateral" são, na verdade, meninas completamente virilizadas portadoras de hiperplasia congênita de supra-renal.

Concluindo, todo paciente com anomalia da diferenciação sexual constitui uma emergência, tanto no sentido de risco de vida (em situações de perda de sal, por exemplo, nas hiperplasias adrenais congênitas) quanto no sentido da integridade psico-social. Tudo que puder ser feito para minimizar o sofrimento tanto do paciente quanto dos familiares é bem-vindo e este é o mote que norteia todos que trabalham neste complexo campo da Endocrinologia, e foi o objetivo do Consenso de Chicago. No entanto, alguns objetivos não foram cumpridos, persistindo uma terminologia dúbia e estigmatizante, e é isto que pretendemos seja revisto nas futuras edições deste Consenso.

\section{REFERÊNCIAS}

1. Sax L. How common is intersex? A response to Anne FaustoSterling. J Sex Res 2002;39:174-8.

2. Maciel-Guerra AT, Guerra-Júnior G. Menino ou menina? Os distúrbios da diferenciação do sexo. São Paulo: Editora Manole, 2002.

3. Dreger AD, Chase C, Sousa A, Gruppuso PA, Frader JB. Changing the nomenclature/taxonomy for intersex: a scientific and clinical rationale. J Pediatr Endocrinol Metab 2005; 18:729-33.

4. Maciel-Guerra AT, Guerra-Júnior G. Determinação e diferenciação do sexo. Arq Bras Endocrinol Metab 2005;49:1171.

5. Nelson CP, Gearhart JP. Current views on evaluation, management, and gender assignment of the intersex infant. Nat Clin Pract Urol 2004;1:38-43.

6. Frimberger D, Gearhart JP. Ambiguous genitalia and intersex. Urol Int 2005;75:291-7.

7. MacGillivray $\mathrm{MH}$, Mazur T. Intersex. Adv Pediatr 2005;52:295-319.

8. Brown J, Warne G. Practical management of the intersex infant. J Pediatr Endocrinol Metab 2005;18:3-23. 
9. Ahmed SF, Morrison S, Hughes IA. Intersex and gender assignment: the third way? Arch Dis Child 2004;89:847-50.

10. Lee PA. A perspective on the approach to the intersex child born with genital ambiguity. J Pediatr Endocrinol Metab 2004:17:133-40

11. Migeon CJ, Wisniewski AB. Human sex differentiation and its abnormalities. Best Pract Res Clin Obstet Gynaecol 2003;17:1-18.

12. Sultan C, Paris F, Jeandel C, Lumbroso S, Galifer RB. Ambiguous genitalia in the newborn. Semin Reprod Med 2002;20:181-8.

13. Hughes IA. Intersex. BJU Int 2002;90:769-76.

14. Damiani D, Setian N, Kuperman H, Manna TD, Dichtchekenian V. Genitália ambígua: diagnóstico diferencial e conduta. Arq Bras Endocrinol Metab 2001;45:37-47.

15. Hughes IA, Houk C, Ahmed SF, Lee PA; LWPES1/ESPE2 Consensus Group. Consensus statement on management of intersex disorders. Arch Dis Child 2006;91:554-62.
16. Houk CP, Lee PA, Rapaport R. Intersex classification scheme: a response for the call for a change. J Pediat Endocrinol Metab 2005; $18: 735-8$.

17. Resolução CFM № $1.664 / 2003$. Define as normas técnicas necessárias para o tratamento de pacientes portadores de anomalias de diferenciação sexual. Disponível em: <http://www.portalmedico.org.br/resolucoes/cfm/2003/1664_ 2003.htm>. Acessado emOutubro de 2006.

Endereço para correspondência:

Durval Damiani

Rua Bela Cintra 2117, apto. 9

01415-002 São Paulo, SP

E-mail: durvald@iconet.com.br 